Case report

\title{
Ziprasidone-related oculogyric crisis in an adult
}

\author{
Bernardo de Mattos Viana ${ }^{\mathrm{a}, *}$, Hugo Alejandro Cano Prais ${ }^{\mathrm{b}}$, Sarah Teixeira Camargos ${ }^{\mathrm{c}, \mathrm{d}}$, \\ Francisco Eduardo Costa Cardoso ${ }^{\mathrm{c}, \mathrm{d}}$ \\ a Psychiatry Service, Hospital das Clínicas (HC-UFMG), Federal University of Minas Gerais, Av. Alfredo Balena, 110, Santa Efigênia, Belo Horizonte (MG), 30130-100, Brazil \\ ${ }^{\mathrm{b}}$ Department of Medical Sciences, Federal University of Ouro Preto, Ouro Preto (MG), Brazil \\ ' Movement Disorders Clinic, Neurology Service, Hospital das Clínicas (HC-UFMG), Federal University of Minas Gerais, Belo Horizonte (MG), Brazil \\ d Department of Internal Medicine, School of Medicine, Federal University of Minas Gerais, Belo Horizonte (MG), Brazil
}

\section{A R T I C L E I N F O}

\section{Article history:}

Received 23 December 2008

Received in revised form 16 July 2009

Accepted 25 July 2009

Available online 29 August 2009

\section{Keywords:}

Oculogyric crisis

Ziprasidone

Tardive dyskinesia

Acute dystonia

Drug-induced dyskinesia

\begin{abstract}
A B S T R A C T
Introduction: Drug-induced dyskinesias are common side-effects of first-generation antipsychotics (FGAs) but are not usually related to second-generation antipsychotics (SGAs). Oculogyric crisis (OGC) is a disabling acute dystonia that affects extra-ocular muscles usually resulting in an upward deviation of the eyes, which lasts from minutes to hours.

Case report: We describe an adult patient, previously exposed to an FGA, who developed OGC on $80 \mathrm{mg} / \mathrm{day}$ of ziprasidone. The movement disorder significantly improved after use of $1 \mathrm{mg} /$ day of clonazepam without the need to switch to another SGA.

Discussion: The clinical features of the movement disorder of our patient meet the criteria for OGC. It is, sometimes, difficult to directly correlate a drug-induced dyskinesia to a SGA due to previous exposures to FGAs. The onset of OGC after exposure to ziprasidone without simultaneous use of other antipsychotic suggests a casual relationship between the former and the movement disorder. It is possible that previous use of an FGA was a risk factor for the development of OGC.

Conclusion: To the best of our knowledge, this is the first report of ziprasidone-related OGC in an adult patient. Physicians must be aware of its occurrence in order to improve care of patients treated with these agents.
\end{abstract}

(c) 2009 Elsevier B.V. All rights reserved.

\section{Introduction}

Drug-induced dyskinesias are common motor disorders often related to exposure to first-generation antipsychotics (FGAs) occurring in any moment of their use. They can be classified as acute dystonias and tardive dyskinesias [1,2]. Ziprasidone is a benzisothiazolyl compound with a high $5 \mathrm{HT}_{2 \mathrm{~A}} / \mathrm{D}_{2}$ receptor-affinity ratio of antagonism, $5 \mathrm{HT}_{2} \mathrm{C}$ antagonism, $5 \mathrm{HT}_{1 \mathrm{~A}}$ partial agonism and serotonin and noradrenaline reuptake inhibitor [1]. As a secondgeneration antipsychotic (SGA), it has a relatively low risk of motor side-effects $[1,2]$. Oculogyric crisis (OGC) is an acute dystonia, which affects the extra-ocular muscles and usually results in upward deviation of the eyes [2,3]. It is a common acute side-effect with reports of frequency of $10-60 \%$ among patients exposed to antipsychotic agents [4,5]. Younger age, male gender and first few days of treatment are considered risk factors of its occurrence [1,2]. While there are two reports of OGC related to ziprasidone in teenagers [6,7], to the best of our knowledge

\footnotetext{
* Corresponding author. Tel.: +55 31 34099458; fax: +55 3134099458 .

E-mail address: bernardomviana@yahoo.com (B.d.M. Viana).
}

this is the first published case of OGC related to ziprasidone in an adult.

\section{Case report}

A 28-year-old female was brought to our psychiatric out-patient unit to continue her treatment previously started elsewhere. She was diagnosed with schizophrenia at the age of 15 due to persistent mystic delusions, auditory hallucinations and psychomotor agitation. There was no family history of neurological or psychiatric disease. Since that time she was treated with haloperidol with poor compliance. However, at the age of 24 she developed upward deviation of the eyes and blefarospasm for $2 \mathrm{~h}$. She denied loss of consciousness, visual hallucinations, torticollis or opisthotonus. The frequency of the episodes was 2 or 3 per week, which were considered as related to the neuroleptic. As she did not obtain clinical control with anti-cholinergic agents, haloperidol was changed to ziprasidone ( $80 \mathrm{mg} /$ day). During the first 7 months of treatment, the patient did not develop OGC. Later, however, there was the recurrence of this movement disorder with the frequency of up to 3 episodes a month. Work up included an EEG which failed to show epileptic discharges. As she did not improve previously with 
biperiden, we started clonazepam $1 \mathrm{mg} / \mathrm{day}$. She remained free of OGC for 8 months, but 3 days after withdrawal of clonazepam the movement disorder recurred.

\section{Discussion}

Acute drug-induced dyskinesias are generally related to introduction of an antipsychotic or after an increase of its dosage. The first signs occur within $48 \mathrm{~h}$ to 5 days [1-3]. The core clinical feature of OGC is involuntary, sustained, conjugated deviation of the eyes. Accessory features include malaise, pain, restlessness, agitation, other behavioral disturbances and autonomic dysfunction $[4,8]$. It can be accompanied by transient psychotic episodes with visual and auditory hallucinations, ironically induced by high-potency neuroleptics even in non-psychotic patients [8]. This phenomena may lead to an increase, rather than reduction, of medication dosage with subsequent worsening of the condition [8]. Because it often has a long duration (from minutes to hours), OGC may impair the activities of daily living, resulting in severe distress to patients. In addition, it is a meaningful risk factor for treatment discontinuation and, in rare occasions, it may be life-threatening when occurring while driving [1].

Two midbrain pathways seem to play a role in OGC generation. The first one arises from the substantia nigra pars reticulata and ends at the superior colliculi [9]. The second one is the projection from the substantia nigra pars compacta, pars reticulata and the ventral tegmental area to the reticular formation neighboring of the oculomotor nuclei [9]. Lesion of the first pathway is related to paralysis of upward gaze and of the other one to abnormal eye movements [9].

Basal ganglia also seems to be involved since OGC has been reported in Wilson's disease and in patients with focal lesions in basal ganglia and thalamus [10]. Moreover, Sydenham's Chorea with OGC and motor or vocal tics has also been reported [11] as well as in Tourette's disorder and postencephalitic parkinsonism syndrome [12]. Inherited errors of metabolism, such as hyperphenylalaninemia and aromatic amino acid decarboxylase deficiency, can present with OGC although patients usually exhibits other symptoms during neonatal period and childhood [12]. It is important to rule out abnormal eye movement due to seizures, especially in absence epilepsy that may present with associated upward tonic followed by clonic rhythmic upward jerks of the eyes [13].

Tardive dyskinesias related to discontinuation of antipsychotics are generally classified as withdrawal dyskinesia that disappears within 3 months of drug withdrawal or covert dyskinesia, which becomes apparent upon its reduction and persists for longer periods [2]. So far, the sole unquestionable risk factor for tardive dyskinesia is older age [14]. Poor compliance to treatment must be assessed since each time the patient stops and then recommence treatment may lead to acute drug-induced dystonia. There are two reports of tardive OGC related to FGAs $[15,16]$. In these cases, however, the phenomenology is different from the usual acute form of OGC: it lacks pain, the movement disorder often occurs with other phenomena typical of tardive dyskinesia and it worsens with withdrawal of the neuroleptic. There is also the possibility of acute OGC becoming chronically recurrent [16].

The previous reports of ziprasidone-related OGC describe adolescent patients with onset of movement disorders shortly after introduction of neuroleptic [6,7]. Our patient developed OGC during a previous exposure to haloperidol, but after its discontinuation had a symptom free period of more than 6 months. Obviously the recurrence was unrelated to haloperidol. The remission of OGC with simultaneous use of benzodiazepine and ziprasidone rules out TD. A clear response to benzodiazepine is not expected in TD [17], while there are reports of improvement with these agents in acute druginduced OGC $[8,18,19]$. Once TD develops, it is usually persistent with a remission rate of not more than $7.5-14 \%$ in 8.5 -year-follow up studies $[20,21]$. Tardive dystonia is known to be responsive to anti-cholinergic agents and to be more persistent after neuroleptic suspension than TD [2,22], which where neither the case of our patient.

There is an increasing number of reports of drug-induced dyskinesias related to SGAs [23-31]. However, it is difficult to estimate the real prevalence and the direct correlation to an SGA induction, due to previous exposures to FGAs [10], as well as the limited evidence based on case reports.

\section{Conclusion}

To the best of our knowledge, this is the first report of ziprasidone-related OGC in an adult patient. Even though SGAs are good therapeutic options considering the lower incidence of acute side-effects and malignant neuroleptic syndrome, further studies of patients in long-term exposure only to specific SGAs are still necessary. Physicians should be aware of possible occurrence of drug-induced dyskinesias in association with these agents. Recognizing the characteristics of these side-effects such as onset and duration is important to select the best therapeutic strategy. Acute persistent movement disorders have obvious implications to adherence and response to treatment.

\section{References}

[1] Janicak PG, Davis JM, Preskorn SH, Ayd Jr FJ, Marder SR, Pavuluri MN, editors. Treatment with antipsychotics. In: Principles and practice of psychopharmacotherapy. 4th edition Philadelphia: Lippincott Williams \& Wilkins; 2006. p. 81-182.

[2] Sethi KD, Morgan JC. Drug-induced movement disorders. In: Jankovic J, Tolosa E, editors. Parkinson's disease \& movement disorders. 5th edition Philadelphia: Lippincott Williams \& Wilkins; 2007. p. 394-408.

[3] Swett C. Drug-induced dystonia. Am J Psychiatry 1975;132:532-4.

[4] Owens DGC. Dystonia-a potential psychiatric pitfall. Br J Psychiatry 1990;156:620-34.

[5] Remington GJ, Voineskos G, Pollock B, Reed K, Coulter K. Prevalence of neuroleptic-induced dystonia in mania and schizophrenia. Am J Psychiatry 1990;147:1231-3.

[6] Ramos AE, Shytle RD, Silver AA, Sanberg PR. Ziprasidone-induced oculogyric crisis. J Am Acad Child Adolesc Psychiatry 2003;42:1013-4.

[7] Gupta S, Nolan TN, Frank BL. Case report of oculogyric crisis with ziprasidone in a minor. Prim Care Companion J Clin Psychiatry 2008;10:254-5.

[8] Abe K. Psychiatric symptoms associated with oculogyric crisis: a review of literature for the characterization of antipsychotic-induced episodes. World J Biol Psychiatry 2006;7:70-4.

[9] Devinsky O. Neuroanatomy of Gilles de la Tourette's syndrome. Possible midbrain involvement. Arch Neurol 1983;40:508-14.

[10] Lee MS, Kim YD, Lyoo CH. Oculogyric crisis as an initial manifestation of Wilson's disease. Neurology 1999;52:1714-5.

[11] Cardoso F, Eduardo C, Silva AP, Mota CC. Chorea in fifty consecutive patients with rheumatic fever. Mov Disord 1997;12:701-3.

[12] Jankovic J, Tolosa E. Parkinson's disease \& movement disorders. 5th edition Philadelphia: Lippincott Williams \& Wilkins; 2007.

[13] Bogacz J, Bogacz D, Bogacz A. Oculomotor phenomena in petit-mal. Clin Neurophysiol 2000;111:959-63.

[14] Tarsy D, Baldessarini RJ. Epidemiology of tardive dyskinesia: is risk declining with modern antipsychotics? Mov Disord 2006;21:589-98.

[15] FitzGerald P, Jankovic J. Tardive oculogyric crises. Neurology 1989;39:1434-7.

[16] Sachdev P, Tardive. Chronically recurrent oculogyric crises. Mov Disord 1993;8:93-7.

[17] Bhoopathi PS, Soares-Weiser K. Benzodiazepines for neuroleptic-induced tardive dyskinesia. Cochrane Database Syst Rev 2003;(2):CD000205.

[18] Reeves AL, So EL, Sharbrough FW, Krahn LE. Movement disorders associated with the use of gabapentin. Epilepsia 1996;37:988-90.

[19] Horiguchi J, Inami Y. Effect of clonazepam on neuroleptic-induced oculogyric crisis. Acta Psychiatr Scand 1989;80:521-3.

[20] Kiriakakis V, Bhatia KP, Quinn NP, Marsden CD. The natural history of tardive dystonia, a long-term follow-up study of 107 cases. Brain 1998;121:2053-66.

[21] Kang UJ, Burke RE, Fahn S. Natural history and treatment of tardive dystonia Mov Disord 1986;1:193-208.

[22] Burke RE, Fahn S, Jankovic J, Marsden CD, Lang AE, Gollomp S, et al. Tardive dystonia: late-onset and persistent dystonia caused by antipsychotic drugs. Neurology 1982;32:1335-46. 
[23] Bilal L, Tsai C, Gasper JJ, Ndlela JC. Parkinsonism with intramuscular ziprasidone. Am J Psychiatry 2005;162:2392-3.

[24] Mason MN, Johnson CE, Piasecki M. Ziprasidone-induced acute dystonia. Am J Psychiatry 2005;162:625-6.

[25] Weinstein SK, Adler CM, Strakowski SM. Ziprasidone-induced acute dystonic reactions in patients with bipolar disorder. J Clin Psychiatry 2006;67: 327-8.

[26] Mellacheruvu S, Norton JW, Schweinfurth J. Atypical antipsychotic druginduced acute laryngeal dystonia: 2 case reports. J Clin Psychopharmacol 2007;27:206-7.
[27] Keck ME, Müller MB, Binder EB, Sonntag A, Holsboer F. Ziprasidone-related tardive dyskinesia. Am J Psychiatry 2004;161:175-6.

[28] Papapetropoulos S, Wheeler S, Singer C. Tardive dystonia associated with ziprasidone. Am J Psychiatry 2005;162:2191.

[29] Tsai CS, Lee Y, Chang YY, Lin PY. Ziprasidone-induced tardive laryngeal dystonia: a case report. Gen Hosp Psychiatry 2008;30:277-9.

[30] Rosenquist KJ, Walker SS, Ghaemi SN. Tardive dyskinesia and ziprasidone. Am J Psychiatry 2002;159:1436.

[31] Ananth J, Burgoyne KS, Niz D, Smith M. Tardive dyskinesia in 2 patients treated with ziprasidone. J Psychiatry Neurosci 2004;29:467-9. 